Original Research Article

\title{
A study on chronicity and treatment response of functional abdominal pain in 5 to 15 years of children, in relation to size and location of primary mesenteric lymphadenitis in a tertiary care centre
}

\author{
Das Kumar S. ${ }^{1}$, Subudhi M. ${ }^{2}$ \\ ${ }^{1}$ Dr. Sudhanshu Kumar Das, Associate Professor, Department of Pediatrics, ${ }^{2}$ Dr. Monalisa Subudhi, Assistant Professor, \\ Department of Microbiology, Gayatri Vidya Parishad Institute of Healthcare \& Medical Technology, Visakhapatnam, Andhra \\ Pradesh, India.
}

Corresponding Author: Dr. Monalisa Subudhi, Department of Microbiology, Gayatri Vidya Parishad Institute of Healthcare \& Medical Technology, Visakhapatnam, Andhra Pradesh, India. E-mail: aryashdas@gmail.com

\begin{abstract}
Introduction: Functional abdominal pain (FAP) is one of the most common childhood complaints, an intermittent (recurrent abdominal pain or RAP) or continuous in nature, which cannot be explained by any visible or detectable abnormality, after a thorough physical examination and appropriate laboratory testing. It has negative effects on the child's physical and psychological state and interfere their daily activities. The present study aimed to find out the chronicity and treatment response of functional abdominal pain in relation to size and site of location of in primary mesenteric lymphadenitis. Methodology: A prospective study was done on 156 patients, aged 5 to 15 years, in the department of paediatric of GVPMC, Visakhapatnam, AP, a tertiary care hospital, from September 2017 to March 2019. Patient's demographic profile, clinical features, physical examination and systemic examination were recorded. All the relevant investigations were done in all the patients. For the purpose of the study, all cases were categorised into four group, according to their site of pain. The presence of enlarged mesenteric lymph nodes, their location, size (transverse and anteroposterior dimensions) and other significant findings were recorded. Mesenteric lymphadenopathy was labeled significant using a short axis diameter of $>5 \mathrm{~mm}$ in short axis diameter. Final diagnosis was established, and patients were followed in OPD. Result: Majority of children presented with abdominal pain, under 5 to 10 years age were female $38(51.35 \%)$ and $52(63.41 \%)$ were male under 11 to 15 years. Most common abdominal site of Mesenteric lymph node enlargement was Periumbilical site followed by Right Iliac Fossa. According to the site of pain, Majority of the cases were under group I, 54 (34.61\%) and group III, 42 (26.92\%). In four groups, all relieved cases had lymph node of size $5 \mathrm{~mm}$ to $8 \mathrm{~mm}$, except group III $16(10.25 \%)$ cases and all persistent cases, lymph node size more than 8mm, except group II 20 (12.82\%). Conclusion: Good approach can be obtained to these cases early and follow up regularly to, modify their painful early school life and assure the parents about the benign nature of the disease.
\end{abstract}

Keywords: FAP (Functional abdominal pain), Recurrent abdominal pain (RAP), Chronic functional abdominal pain (CFAP)), Mesenteric lymph node (MLN)

\section{Introduction}

Functional abdominal pain (FAP) is abdominal pain that cannot be explained by any visible or detectable abnormality, after a thorough physical examination and appropriate laboratory testing. It is one of the most common childhood and adolescent complaints. It can be intermittent (recurrent abdominal pain or RAP) or continuous. Here the gut is more sensitive to some trigger that normally do not cause significant pain, is due to either nerve signals or chemicals secreted by it. Usually, the pain

Manuscript received: $6^{\text {th }}$ November 2019

Reviewed: $16^{\text {th }}$ November 2019

Author Corrected: $24^{\text {th }}$ November 2019

Accepted for Publication: $29^{\text {th }}$ November 2019 is located around the umbilicus; however, the pattern or location of abdominal pain is not always predictable. Mesenteric lymphadenitis is commonly reported in children with functional abdominal pain [1]. Cluster of three or more enlarged mesenteric lymph nodes that are each $5 \mathrm{~mm}$ or greater in the short axis, in the absence of other abnormalities is termed as primary mesenteric lymphadenitis [2].

Primary, mesenteric lymphadenitis is a self-limiting inflammatory condition affecting mostly right-sided mesenteric lymph nodes $[3,4,5]$. The distribution of pain, 
like that of appendicitis, is felt both in the periumbilical region and in the right iliac fossa [6]. Tenderness is maximal in the right iliac fossa but is often present higher up towards the epigastrium. In the current study, our aim is to know, the chronicity and treatment response of functional abdominal pain in relation to size and site of location of in primary mesenteric lymphadenitis.

\section{Materials \& Methods}

This study was done prospectively, over a period of two years from September 2017 to August 2019, on 156 patients, aged 5 to 15 years, who attended the OPD with abdominal pain in the department of paediatric of GVPMC, Visakhapatnam, AP, a tertiary care hospital, with institutional ethical approval.

\section{Inclusion criteria:}

1. Children having at least three episodes of pain that occur over at least three months period and that affect the child's ability to perform normal activities.

\section{Exclusion criteria:}

1. Recurrent abdominal pain associated with headache, nausea, vomiting, anorexia, altered bowel movement.

2. Features suggestive of underlying organic pathology like - Involuntary weight loss. Falling off growth centiles. Gastrointestinal blood loss. Significant vomiting. Chronic severe diarrhoea.

Unexplained fever, Abnormal physical signs such as pallor, jaundice, guarding, rebound tenderness, altered bowel sounds, or a palpable mass.

Patient's demographic profile (Name, Age, Sex), clinical features, physical examination and systemic examination were recorded.
All the relevant investigations like complete blood count, Urine analysis, stool test and ultrasonography of abdomen were evaluated in all the patients.

The presence of enlarged mesenteric lymph nodes, their location, size (transverse and anteroposterior dimensions) and other significant findings were recorded.

The patients with positive finding in USG i.e. significant enlargement of mesenteric lymph nodes and a slight thickening of the terminal ileum wall and/or caecum were followed up to 3 months.

Mesenteric lymphadenopathy was labelled significant using a short axis diameter of $>5 \mathrm{~mm}$ in short axis diameter.

Final diagnosis was established, and patients were followed in OPD.

\section{For the purpose of the study}

- All cases were categorised into four group, according to their site of pain.

- Cases were taken as Acute or Chronic (>3 month) depending on their period of presentation.

- Cases were accepted as Relieved or Persistent case depending on their Response to treatment.

Statistical Analysis- The data was collected using MS excel sheet and analysed. Summarization of data was presented using basic tables.

Clinical and Categorical variables were presented as frequency and percentage.

\section{Result}

In the present study, total 156 patients, aged 5 to 15 years, who attended the OPD with abdominal pain in the department of paediatric of GVPMC, Visakhapatnam, AP, from September 2017 to March 2019 were included.

Table-1: Demographic distribution of study group.

\begin{tabular}{|c|c|c|c|}
\hline \multirow{2}{*}{ Age (Years) } & \multicolumn{2}{|c|}{ Sex } & \multirow{2}{*}{ Total $(\mathrm{n}=156(\%) 0$} \\
\cline { 2 - 4 } & Boys & Girls & \\
\hline $5-10$ & $36(48.64 \%)$ & $38(51.35 \%)$ & $74(47.43 \%)$ \\
\hline $11-15$ & $52(63.41 \%)$ & $30(36.58 \%)$ & $82(52.56 \%)$ \\
\hline
\end{tabular}

Majority of children presented with abdominal pain in the present study group, were female 38 (51.35\%) as compared to male $36(48.64 \%)$ under 5 to 10 years age. Again, most of the children were male $52(63.41 \%)$ under 11 to 15 years of age group (Table1). 
Original Research Article

Table-2: Distribution of study group according to Chronicity and Treatment Response in relation to site \& size of mesenteric Lymphnode.

\begin{tabular}{|c|c|c|c|c|c|c|c|c|}
\hline \multicolumn{9}{|c|}{ Functional abdominal pain } \\
\hline & & & & & $\begin{array}{c}\text { Freque } \\
\operatorname{ncy}(f)\end{array}$ & $\begin{array}{c}\text { Duratio } \\
\text { n each } \\
\text { episode }\end{array}$ & $\begin{array}{c}\text { Follow-up } \\
\text { period } \\
\text { (Acute / } \\
\text { Chronic) }\end{array}$ & $\begin{array}{c}\text { Relieved } \\
/ \\
\text { Persistent }\end{array}$ \\
\hline \multirow{2}{*}{$\begin{array}{l}\text { Grou } \\
\text { p(n) }\end{array}$} & \multirow[t]{2}{*}{ Site of Pain } & \multicolumn{3}{|c|}{ MLN } & & & & \\
\hline & & Site & Size & $\begin{array}{c}\text { No of } \\
\text { Case(n) }\end{array}$ & & & & \\
\hline \multirow[b]{2}{*}{$\begin{array}{c}\mathbf{I} \\
(54)\end{array}$} & \multirow{2}{*}{$\begin{array}{l}\text { Epigastric + } \\
\text { Peri-umbilical + } \\
\text { Hypogastrium }\end{array}$} & \multirow[t]{2}{*}{ RIF } & $5-8 \mathrm{~mm}$ & $32(20.5 \%)$ & 1/week & $2 \mathrm{hr}$ & $2 \mathrm{~m}$ & Relieved \\
\hline & & & $>8 \mathrm{~mm}$ & $22(14.10 \%)$ & 1/week & $1 \mathrm{dy}$ & $4 \mathrm{~m}$ & Persistent \\
\hline \multirow{2}{*}{$\begin{array}{c}\text { II } \\
(35)\end{array}$} & \multirow{2}{*}{$\begin{array}{l}\text { Periumbilical+ } \\
\text { RIF }\end{array}$} & \multirow[t]{2}{*}{ Umblilical } & $5-8 \mathrm{~mm}$ & $20(12.82 \%)$ & 2/week & $2 \mathrm{dy}$ & $6 \mathrm{~m}$ & Persistent \\
\hline & & & $>8 \mathrm{~mm}$ & $15(9.61 \%)$ & 3/week & $18 \mathrm{hr}$ & $6 \mathrm{~m}$ & Persistent \\
\hline \multirow{2}{*}{$\begin{array}{c}\text { III } \\
(42)\end{array}$} & \multirow{2}{*}{$\begin{array}{l}\text { Periumbilical+ } \\
\text { Epigastrium }\end{array}$} & \multirow{2}{*}{$\begin{array}{l}\text { Periumbilical } \\
\& \text {, Epigastrium }\end{array}$} & $5-8 \mathrm{~mm}$ & $26(16.66 \%)$ & 1/week & $18 \mathrm{hr}$ & $3 \mathrm{~m}$ & Relieved \\
\hline & & & $>8 \mathrm{~mm}$ & $16(10.25 \%)$ & 3/week & $2 \mathrm{hr}$ & $2 \mathrm{~m}$ & Relieved \\
\hline \multirow{2}{*}{$\begin{array}{c}\text { IV } \\
(25)\end{array}$} & \multirow{2}{*}{$\begin{array}{l}\text { Peri-umbilical + } \\
\text { RIF + Left Iliac } \\
\text { fossa }\end{array}$} & \multirow[t]{2}{*}{ Umblilical } & $5-8 \mathrm{~mm}$ & $15(9.61 \%)$ & 3/day & $2 \mathrm{hr}$ & $2 \mathrm{~m}$ & Relieved \\
\hline & & & $>8 \mathrm{~mm}$ & $10(6.41 \%)$ & $3 /$ week & $24 \mathrm{hr}$ & $1 \mathrm{yr}$ & Persistent \\
\hline
\end{tabular}

Most common abdominal site of Mesenteric lymph node enlargement was Periumbilical site followed by Right Iliac Fossa. According to the site of pain, Majority of the cases were under group I, 54 (34.61\%) and group III, 42 (26.92\%). In four groups, all relieved cases had mesenteric lymph node of size $5 \mathrm{~mm}$ to $8 \mathrm{~mm}$, except group III 16 (10.25\%) cases, where the size was $>8 \mathrm{~mm}$ with prolonged period of. All relieved cases were acute cases with duration of less than 3 month. All persistent cases were more than 6-month duration, with mesenteric lymph node of size more than 8mm, except group II 20 (12.82\%) cases with prolonged period of pain (each episode 24 to 48 hours) (Table 2).

\section{Discussion}

Chronic functional abdominal pain (CFAP) is the ongoing presence of abdominal pain for which there is no known medical explanation [7]. It is quite similar to, but less common than, irritable bowel syndrome(IBS), and many of the same treatments for IBS can also be of benefit to those with CFAP. The fundamental difference between IBS and CFAP is that in CFAP, unlike in IBS, there is no change in bowel habits such as constipation or diarrhoea. Bowel dysfunction is a necessary diagnostic criterion of IBS.

CFAP is characterized by chronic pain, with no physical explanation or findings (no structural, infectious, or mechanical causes can be found). It is theorized that CFAP is a disorder of the nervous system where normal nociceptive nerve impulses are amplified, resulting in pain. This visceral hypersensitivity may be a standalone cause of CFAP, or CFAP may result from the same type of brain-gut nervous system disorder that underlies IBS [8]. In the present study, even though girls were more under 5to 10 years of children, both boys and girls were almost equally affected. Increased prevalence in girls has led to suggestions that levels of sex hormones might play a role in these cases. So also. Ovarian hormones can modulate both visceral pain perception and the susceptibility to stress [9]. Mesenteric lymphadenitis typically occurs in children, adolescents, and young adults of both sexes, although males might be slightly more frequently affected than females $[10,11,12]$. In the present study, children under 11 to 15 years of age, boys were significantly higher in number than girls. The low incidence of cases in girls, in this age group in my study, could be explained by the fact that, the female child's nutrition and health may be neglected in our society.

Most common site of pain, in the present study, was periumbilical pain could be due to a number of causes. In several studies, it was found that, the small and large bowel with dysmotility and variations in transit time were documented as common cause of periumbilical pain, [13] Primary or nonspecific mesenteric lymphadenitis has been usually defined as right-sided lymphadenopathy without an identifiable underlying inflammatory cause.

In these patients, there are no further imaging abnormalities, except for a slight thickening of the terminal ileum wall and caecum in a minority of cases, which was found to be the same in the present study [14]. In most cases of mesenteric lymphadenitis, an underlying viral infectious terminal ileitis is thought to be the cause. 
Original Research Article

\section{Conclusion}

By knowing the chronicity and treatment response to FAP, good approach can be obtained to these cases early and will follow up regularly to modify their painful early school life, mental state and the consequences. The present study can assure the parents about the benign nature of the disease

\section{What the study adds to the existing knowledge?}

There should be more study on this area of concern required, to approach and to reach a conclusion about how to give a better quality of life to these children.

\section{Author's Contribution}

Dr. Sudhanshu Kumar Das: Manuscript writing.

Dr. Monalisa Subudhi: designed the study, performed the analytic calculations and performed the numerical simulations.

Funding: No funding sources

Conflict of interest: None declared

Ethical Approval: This study was approved by the Institutional Ethics Committee

\section{References}

1. Karmazyn B, Werner EA, Rejaie B, Applegate KE. Mesenteric lymph nodes in children: what is normal? Pediatr Radiol. 2005;35(8):774-777.doi: https://doi. org/ $10.1007 / \mathrm{s} 00247-005-1462-2$.

2. Macari M, Hines J, Balthazar E, Megibow A., Mesenteric adenitis: CT diagnosis of primary versus secondary causes, incidence, and clinical significance in pediatric and adult patients. AJR 2002; 178 (4):853-858. doi: https://doi.org/10.2214/ajr.178.4.1780853.

3. Blattner RJ. Acute mesenteric lymphadenitis. J Pediat. 1969;74(3):479-481. doi: https://doi.org/10.1016/S00223476(69)80210-6.

4. Jones PF. Acute abdominal pain in childhood, with special reference to cases not due to acute appendicitis. Brit Med J.1969;1(5639):284-286. doi: https://doi.org/10. 1136/bmj.1.5639.284.
5. Macari M, Hines J, Balthazar E,Megibow A. Mesenteric adenitis: CT diagnosis of primary versus secondarycauses, incidence, and clinical significance in pediatric and adult patients.Am J Roentgenol. 2002; 178(4):853-858. Doi: https://doi.org/10.2214/ajr.178.4.1780853.

6. Chanchlani R. Clinical profile and management of mesenteric lymphadenitis in children - our experience. Int J Orthopaed, Traumatol Surg Sci. 2015;1(1):1-4

7. Clouse RE, Mayer EA, Aziz Q, Drossman DA, Dumitrascu DL, Mönnikes H, et al. Functional abdominal pain syndrome. Gastroenterol. 2006;130(5):1492-1497. doi:https://doi.org/10.1053/j.gastro.2005.11.062.

8. Drossman DA. Functional gastrointestinal disorders: history, pathophysiology, clinical features, and Rome IV. Gastroenterol.2016;150(6):1262-1279.doi: https: // doi.org / 10. 1053/j.gastro.2016.02.032. [Epub ahead of print].

9. Korterink JJ, Diederen K, Benninga MA, Tabbers MM. Epidemiology of Pediatric Functional Abdominal Pain Disorders: AMeta-Analysis. PLoSONE. 2015; 10(5):e 0126982. doi: https://doi.org/10.1371/ journal. pone. 0126982

10. Helbling R, Conficconi E, Wyttenbach M, Benetti C, Simonetti GD, Bianchetti MG, et al. Acute nonspecific mesenteric lymphadenitis: more than "no need for surgery".BioMed research international.2017;2017. doi: https://doi.org/10.1155/2017/9784565.

11. Siegel MJ, Carel C, Surratt S. Ultrasonography of acute abdominal pain in children. Jama. 1991;266(14): 1987-1989. doi: https://doi.org/10.1001/ jama. 1991. 03470140099032 .

12. Toorenvliet B, Vellekoop A, Bakker R, Wiersma F, Mertens B, Merkus J, et al. Clinical differentiation between acute appendicitis and acute mesenteric lymphadenitis in children. Europe J Pediat Surg. 2011;21 (2):120-123.doi: https://doi.org/10.1055/s-0030-1267979.

13. Kellow JE, Delvaux M, Azpiroz F, Camilleri M, Quigley EM, Thompson DG. Principles of applied neurogastroenterology:physiology/motility-sensation.Gut. 1999; 45 (2): II17-II24. doi: http://dx.doi.org/10.1136/gut. 45. 2008. ii 17 .

14. Rao P. M., Rhea JT, Novelline RA. CT diagnosis of mesenteric adenitis. Radiol. 1997;202(1): 145-149. doi: https://doi.org/10.1148/radiology.202.1.8988204.

\section{How to cite this article?}

Das Kumar S, Subudhi M. A study on chronicity and treatment response of functional abdominal pain in 5 to 15 years of children, in relation to size and location of primary mesenteric lymphadenitis in a tertiary care centre. Int J Pediatr Res.2019; 6(12):602-605.doi:10.17511/ijpr.2019.i12.03 